\title{
The Behavioural Intentions of Secondary School Students to Use Tablet as a Mobile Learning Device
}

\author{
https://doi.org/10.3991/ijim.v14i13.13027 \\ Wan Mohd Amir Fazamin Wan Hamzah ${ }^{(凶)}$, Hafiz Yusoff, Ismahafezi Ismail \\ Universiti Sultan Zainal Abidin, Terengganu, Malaysia \\ amirfazamineunisza.edu.my \\ Azliza Yacob \\ TATI University College, Terengganu, Malaysia
}

\begin{abstract}
Advances in technology have allowed mobile devices to be used for learning purpose. The use of tablets in mobile learning has the potential to enhance learning, contributing to increased motivation and knowledge acquisition. However, without careful planning and support for learning content, students may not have the behavioural intention to use tablets in their learning. Previous studies have focused on the use of learning applications installed in the tablets. There is a lack of research on students' behavioural intentions to use tablets in learning. The partial least squares regression approach and the Unified Theory of Acceptance and Use of Technology (UTAUT) were used in this study to explore students' behavioural intention to use the tablet in learning. This study was conducted in a private school in Malaysia. A total of 170 participants were enrolled in this study. The results showed that most of the hypotheses of the study were not supported and further revealed that the construct of performance expectancy was the only determinant of students' behavioural intentions to use the tablet in learning.
\end{abstract}

Keywords - Behavioural intentions, UTAUT, tablet, mobile learning.

\section{$1 \quad$ Introduction}

The use of mobile technology in learning is growing with time [1]. The advances in mobile technology and development of wireless Internet access have led to the growth of mobile learning [2][3], which allows students to enjoy personalised learning on their mobile devices.

Mobile learning using tablets has the potential to enhance learning, contributing to increased motivation and knowledge acquisition [4][5][6][7]. The study by Haßler [8] classified three categories of findings for tablet use in supporting mobile learning; positive learning outcomes, no difference in learning outcomes and adverse learning outcomes. It was found that there was an excellent potential for researching tablet to be used in schools, especially as technology becomes more accessible and affordable [9]. 
Most studies involving the use of tablets have previously focused on the use of learning applications installed on the tablet [10][11][12][13]. There is a lack of research on students' behavioural intentions to use tablets as mobile learning devices in schools. Providing a learning app for mobile learning does not guarantee that students will use it in their learning. The purpose of this study is to explore students' behavioural intentions to use tablets in school. A research model based on the current theory of technology adoption, Unified Theory of Acceptance and Use of Technology (UTAUT) was developed with four research hypotheses proposed. The UTAUT theory is often used to clarify individual usage behaviours associated with information systems [12][13][14]. The research model developed was empirically tested using data collected from the students at a private secondary school in Malaysia. The results of this study can be used to evaluate the return on investment in tablet use in school learning.

\section{$2 \quad$ Literature Review}

\subsection{Mobile learning}

Mobile learning is a specialised learning environment that leverages mobile technology through handheld devices and wireless networks. Mobile learning is a part of elearning [17]. Other researchers have focused more on students and learning experiences, but the underlying principles remained the same [18][19]. Mobile learning is also a term commonly used to refer to the delivery of information that leads to learning. Students have been actively seen to gain knowledge when using mobile devices to interact with learning objects anytime and anywhere [20].

Various mobile devices have been used in learning such as smartphones, tablets and the Raspberry Pi [21][22][23][24][25]. Tablets are mobile devices that integrate multiple components and sensors in a device, typically with a built-in global touchscreen, camera and global positioning system (GPS). The popularity of tablets has spurred interest in apps in education, especially in schools.

Tablets are used to support various learning activities in science learning activities such as water cycles [6], plant morphology [23][24] and dynamics the food chain [28]. For Social Studies activities, tablets are used to support financial and economic management activities [29]. Whereas for Math subjects, tablets are used to support fractional-related activities [30]. Additionally, they are also used to support economic learning activities [12] and historical learning [31].

\subsection{Behavioural intentions}

Previous studies described several models developed to evaluate users' attitudes and intentions to adopt new technologies or information systems. These models include the Technology Acceptance Model (TAM) [32], the Theory of Planned Behaviour (TPB) [33], the Innovation Diffusion Theory (IDT) [34], and the Unified Theory Of Acceptance and Use of Technology (UTAUT) [35]. 
The UTAUT theory combines eight models, namely the Theory of Reasoned Action, the Model of Personal Computer Utilisation, the Social Cognitive Theory, the Technology Acceptance Model, the Theory of Planned Behavior, the Innovation Diffusion Theory, the Motivational Model, the combined Technology Acceptance Model and the Theory of Planned Behaviour.

Venkatesh [35] explained that users' intentions to use a system of technologies and consecutive consumption behaviours are influenced by four main variables; effort expectancy, facilitating conditions, performance expectancy and social influence. The definition of effort expectancy refers to the simple level associated with the use of a system. The facilitating conditions makes it easy to represent that people believe that an organisation exists to maintain the use of systems. The term performance expectancy is the extent to which people are confident that using a given system will help them finding support in their performance. Social influence means that individuals are aware that other prestigious people need to use certain new information systems. By using the UTAUT model, researchers can understand whether or not the technology system meets users' criteria and, in addition, reflects the technology's acceptance of users.

Therefore, UTAUT can be considered an important theoretical factor in exploring students' behavioural intentions to use the tablet in learning for this study. Figure 1 shows a research model developed based on the UTAUT [35].

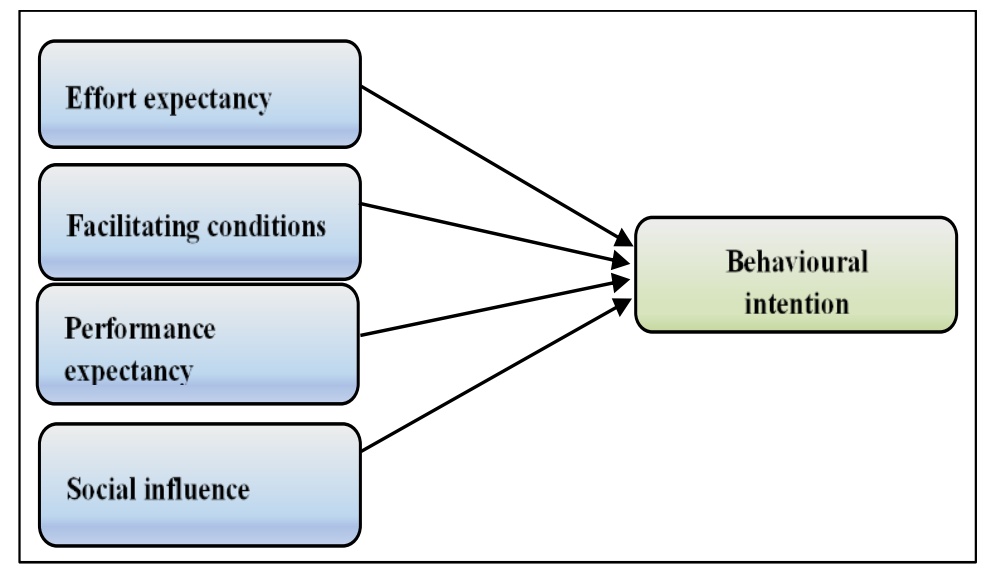

Fig. 1. Behavioural intention model based on the UTAUT

There are two variables in the research model developed in this study namely independent variables and dependent variables. Independent variables consisted of effort expectancy, facilitating conditions, performance expectancy and social influence while the independent variable comprised behavioural intention. The hypotheses of the proposed model are as follow:

i) Effort expectancy will significantly and positively influence students' behavioural intentions to use tablets in learning: Previous literature suggested that 
the issue effort expectancy has been regarded as a significant factor in technology acceptance [36]. Effort expectancy is relevant to the perceived ease of use in the technology acceptance model, which estimates that a system that is easier to use has more possibility to elicit the perception of usefulness and behavioural intention. Moreover, it has been displayed that effort expectancy is an important predictor of behaviour intention through applying the technology acceptance model [32] and the UTAUT [37]. The above studies supported the notion that effort expectancy is substantial to technology use, and it seems that students with high effort expectancy are more likely to use tablet in their learning.

ii) Facilitating conditions will significantly and positively influence students' behavioural intentions to use tablets in learning:The construct of facilitating conditions refers to specific components in the setting that smoothen the system usage to carry out a particular duty [40]. This construct is not similar like other conditions. Explicitly, facilitating conditions consist of resource determinants and technological factors [41]. It is reported that users will not have full aspirations to use a system if they do not have sufficient training or have problems with the mismatch. Therefore, facilitating conditions need to be considered in providing adequate training and support. In this study, facilitating conditions had made it easier for students to think that organisations are supportive regarding the use of tablets in learning.

iii) Performance expectancy will significantly and positively influence students' behavioural intentions to use tablets in learning: Previous studies concerning the acceptance of technology have pointed out that performance expectancy of technology plays an important role in users' behavioural intention [36]. Results from Venkatesh [35] showed that performance expectancy is a strong indicator of how to use technology. Besides, performance expectancy is relevance to influence students' behavioural intentions to use tablets in learning.

iv) Social influence will significantly and positively influence students' behavioural intentions to use tablets in learning: Previous studies have shown that social influence plays a role in changing the intention to use technology [38]. Users tend to communicate more for explaining their use of information technology [39]. Previous study had shown that when inventive technologies are high in uncertainty, people decide whether or not to adapt based on others' point of view [38]. In this study, social influence was referred to the important people for the students who think that they should or should not use the mobile tablet in learning.

\section{Methodology}

\subsection{Sample and procedure}

This study was focused on exploring students' behavioural intentions using tablets in learning. The sample size was 170 students aged between 13 and 17 years old from 
a population of 203 students in a private secondary school. No female students were involved in this study because all students in this school were male. All students used IPAD tablets for learning in school. They have been using tablets for more than six months at the time of this study. Subsequently, students were given a questionnaire to explore their behavioural intentions. Table 1 shows the survey items used in this study. The survey was based on the UTAUT model focusing on students' behavioural intentions to use tablets in learning. Questionnaire used was 5-point Likert scales, where (1) strongly disagree, (2) disagree, (3) neither agree nor disagree, (4) agree and (5) strongly agree. The data were analysed according to the partial least squares regression (PLS). This approach was used to explore their behavioural intentions for using tablets in learning. SmartPLS 3.0 software was used to compute and evaluate the data obtained. The results of this study were based on two models namely measurement and structural models. This study did not involve moderator variables in the UTAUT model such as gender, age, experience and voluntariness of use. All students have similar tablet usage experience based on their demographics.

Table 1. The survey items

\begin{tabular}{|l|l|}
\hline \multirow{5}{*}{ Behavioural Intention } & BI1: I intend to use the tablet in the future. \\
\cline { 2 - 3 } & BI2: I predict that I would use the tablet in the future. \\
\cline { 2 - 2 } & BI3: I plan to use the tablet in the future. \\
\hline & EE1: My interaction with the tablet is clear and understandable. \\
\hline & EE2: It is easy for me to become skilful at using the tablet. \\
\hline & EE3: I find the tablet easy to use. \\
\hline EE4: Learning to operate the tablet is easy for me. \\
\hline Performance Expectancy & FC1: I have the resources necessary to use the tablet. \\
\hline & FC2: I have the knowledge necessary to use the tablet. \\
\cline { 2 - 3 } & $\begin{array}{l}\text { FC3: A specific person (or group) is available for assistance with tablet difficul- } \\
\text { ties. }\end{array}$ \\
\hline & PE2: Using the tablet enables me to learn quickly. \\
\hline & PE3: Using the tablet increases my knowledge. \\
\hline & PE4: If I use the tablet, I will increase my chances of getting good knowledge. \\
\hline SI1: People who influence my behaviour think that I should use the tablet. \\
\hline & SI2: People who are important to me think that I should use the tablet. \\
\hline & SI3: The teacher of this subject has been helpful in the use of the tablet. \\
\hline SI4: In general, the teachers support the use of the tablet. \\
\hline
\end{tabular}

\section{$4 \quad$ Result}

Measurement model was evaluated using item load, convergent validity, reliability of the measure and discriminant validity. Table 2 shows the item loadings for the measurement model. An item is considered reliable if its load is greater than 0.70 [42]. If research is about exploration, 0.4 or higher is acceptable [43]. 
Table 2. The item loadings for the measurement model

\begin{tabular}{|l|c|c|c|}
\hline \multicolumn{1}{|c|}{ Construct } & Loading & Standard Deviation & T- Value \\
\hline BI1 <- Behavioural Intention & 0.884 & 0.022 & 40.209 \\
\hline BI2 <- Behavioural Intention & 0.935 & 0.020 & 47.206 \\
\hline BI3 <- Behavioural Intention & 0.903 & 0.019 & 47.271 \\
\hline EE1 <- Effort Expectancy & 0.821 & 0.035 & 23.732 \\
\hline EE2 <- Effort Expectancy & 0.803 & 0.043 & 18.665 \\
\hline EE3 <- Effort Expectancy & 0.777 & 0.061 & 12.848 \\
\hline EE4 <- Effort Expectancy & 0.587 & 0.095 & 6.147 \\
\hline FC1 <- Facilitating Conditions & 0.811 & 0.044 & 18.343 \\
\hline FC2 <- Facilitating Conditions & 0.824 & 0.047 & 17.701 \\
\hline FC3 <- Facilitating Conditions & 0.578 & 0.103 & 5.630 \\
\hline PE1 <- Performance Expectancy & 0.839 & 0.033 & 25.772 \\
\hline PE2 <- Performance Expectancy & 0.696 & 0.063 & 11.084 \\
\hline PE3 <- Performance Expectancy & 0.860 & 0.030 & 28.702 \\
\hline PE4 <- Performance Expectancy & 0.808 & 0.036 & 22.587 \\
\hline SI1 <- Social Influence & 0.768 & 0.055 & 13.985 \\
\hline SI2 <- Social Influence & 0.761 & 0.057 & 13.332 \\
\hline SI3 <- Social Influence & 0.788 & 0.045 & 17.495 \\
\hline SI4 <- Social Influence & 0.779 & 0.042 & 18.533 \\
\hline
\end{tabular}

Table 3 displays the reliability of measurement and convergence validity. The reliability of the measurements was checked using composite reliability and Cronbach's Alpha. In general, the minimum value of composite reliability is 0.7 and if it is an exploratory research, 0.6 or higher is acceptable [44]. Hair [45] stated that the minimum Cronbach's alpha value is 0.6 . Convergence validity was evaluated through the extracted average variance, which should exceed the standard minimum of 0.5 [44][45]. Discriminant validity as shown in Table 4 was assessed using the square root of the extracted average variance and latent variable correlations. The average squared variance character extracted from each construct should be above the correlation shared between one construct and the other construct in the model [46]. The results shown in Table 2, Table 3 and Table 4 indicated that the measurement model was acceptable since all values met the standard level of exploratory research.

Table 3. The reliability of measures and convergent validity

\begin{tabular}{|c|c|c|c|}
\hline \multirow[t]{2}{*}{ Construct } & \multicolumn{2}{|c|}{ Reliability of Measure } & Convergent Validity \\
\hline & Composite Reliability & Cronbach's Alpha & $\begin{array}{c}\text { Average Variance Ex- } \\
\text { tracted }(A V E)\end{array}$ \\
\hline Behavioural Intention & 0.933 & 0.893 & 0.824 \\
\hline Effort Expectancy & 0.838 & 0.754 & 0.567 \\
\hline Facilitating Conditions & 0.787 & 0.603 & 0.557 \\
\hline Performance Expectancy & 0.878 & 0.814 & 0.645 \\
\hline Social Influence & 0.857 & 0.778 & 0.600 \\
\hline
\end{tabular}


Table 4. The discriminant validity measures

\begin{tabular}{|l|c|c|c|c|c|}
\hline \multirow{2}{*}{\multicolumn{1}{|c|}{ Construct }} & \multicolumn{5}{|c|}{ Discriminant Validity } \\
\cline { 2 - 6 } & $\begin{array}{c}\text { Behavioural } \\
\text { Intention }\end{array}$ & $\begin{array}{c}\text { Effort } \\
\text { Expectancy }\end{array}$ & $\begin{array}{c}\text { Facilitating } \\
\text { Conditions }\end{array}$ & $\begin{array}{c}\text { Performance } \\
\text { Expectancy }\end{array}$ & $\begin{array}{c}\text { Social } \\
\text { Influence }\end{array}$ \\
\hline Behavioural Intention & 0.908 & & & & \\
\hline Effort Expectancy & 0.504 & 0.753 & & & \\
\hline Facilitating Conditions & 0.504 & 0.568 & 0.746 & & \\
\hline Performance Expectancy & 0.559 & 0.612 & 0.599 & 0.803 & \\
\hline Social Influence & 0.509 & 0.579 & 0.650 & 0.585 & 0.774 \\
\hline
\end{tabular}

The hypotheses was validated using path coefficients and $\mathrm{R} 2$ values [42] based on the structural model. The ability of the model was evaluated using R2 to describe the variance in the variables. The path coefficients were used to evaluate the statistical significance of the hypotheses. Figure 2 illustrates the results of the structural model. This model explained $39 \%$ of the variation in behavioural intention. Four path coefficients were also shown in Figure 2. First, the path coefficient between effort expectancy and behavioural intentions was $0.157, \mathrm{p}>0.05$, indicating that effort expectancy did not have any positive and significant influence on behavioural intentions. Second, the coefficient of correlation between facilitating condition and behavioural intentions was 0.140 , $p>0.05$, indicating that facilitating condition did not have any positive and significant influence on behavioural intentions. Third, the path coefficient between performance expectancy and behavioural intentions was $0.285, \mathrm{p}<0.05$, indicating that performance expectancy had a positive and significant influence on behavioural intentions. Fourth, the path coefficient between social influence and behavioural intentions was 0.160 , $\mathrm{p}>0.05$, showing that social influence did not have a positive and significant influence on behavioural intentions. These results demonstrated only one hypothesis that confirmed the predictions, namely performance expectancy, while others rejected them; that are, effort expectancy, facilitating conditions and social influence.

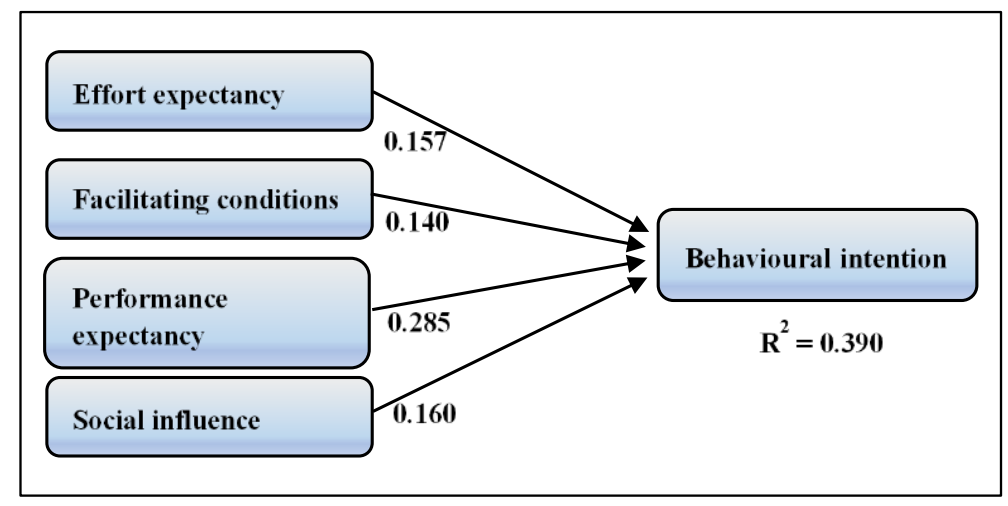

Fig. 2. The result of the analysis 


\section{Discussion and Conclusion}

Based on previous studies, there are positive findings on the use of mobile devices in learning. The effectiveness of the use of mobile devices such as smartphones and tablets in learning is due to learning content, student-content interaction and teacher [47][48][49]. However, this study showed contradictory findings on tablet use in learning. The results of this study showed that only the indicator of performance expectancy positively and significantly influenced students' behavioural intentions to use tablets in learning. Other indicators namely effort expectancy, facilitating conditions and social influence did not influence students' behavioural intention to use tablets for learning.

In conclusion, this study has successfully explored the use of tablets in learning. Students' behavioural intention indicated that they are not yet fully receptive to the use of tablets in learning. The lack of learning content, non-interactive learning applications and their level of readiness to use technology in learning also contributed to the negative findings of the tablet use in learning. Strategic planning needs to be done in the future to optimise the use of technology in the education environment. Future studies should focus on methods to increase the use of the tablet in the mobile learning process.

\section{Acknowledgement}

This research paper supported by Universiti Sultan Zainal Abidin (UniSZA) using FRGS Racer Fund, project number: RACER/1/2019/ICT01/UNISZA//1. Special Thanks to the Ministry of Higher Education Malaysia (MOHE) and Center for Research Excellence \& Incubation management (CREIM) UniSZA for providing financial support for the research.

\section{$7 \quad$ References}

[1] Y. Mcfarlane, A. Triggs, P., \& Wan, "Researching Mobile Learning - Interim Report to Becta Period: April - December 2007," no. December 2007, pp. 1-30, 2008.

[2] G. J. Hwang and C. C. Tsai, "Research trends in mobile and ubiquitous learning: A review of publications in selected journals from 2001 to 2010," Br. J. Educ. Technol., vol. 42, no. 4, pp. 65-70, 2011, https://doi.org/10.1111/j.1467-8535.2011.01183.x

[3] F. Martin and J. Ertzberger, "Here and now mobile learning: An experimental study on the use of mobile technology," Comput. Educ., vol. 68, pp. 76-85, 2013, https://doi.org/10.10 16/j.compedu.2013.04.021

[4] K. J. Kim and T. Frick, "Changes in student motivation during online learning," J. Educ. Comput. Res., vol. 44, no. 1, pp. 1-23, 2011, doi: 10.2190/EC.44.1 a.

[5] C. H. Lai, J. C. Yang, F. C. Chen, C. W. Ho, and T. W. Chan, "Affordances of mobile technologies for experiential learning: The interplay of technology and pedagogical practices,” J. Comput. Assist. Learn., 2007, https://doi.org/10.1111/j.1365-2729.2007.00237.x.

[6] R. Furió Ferri, D.; Juan, M.; Segui, I.; Vivó Hernando, "Mobile learning vs. traditional classroom lessons: A comparative study. Journal of Computer Assisted Learning. 31 ( 3 )," vol. 31, pp. 189-201, 2015, https://doi.org/10.1111/jcal.12071 
[7] M. A. Batsila, C. A. Tsihouridis, and A. H. Tsihouridis, "“All for One and One for All'Creating a mobile learning net for ESP students' needs,” Int. J. Emerg. Technol. Learn., 2017, https://doi.org/10.3991/ijet.v12i04.6428

[8] B. Haßler, L. Major, and S. Hennessy, "Tablet use in schools: A critical review of the evidence for learning outcomes," J. Comput. Assist. Learn., 2016, doi: 10.1111/jcal.12123.

[9] L. Johnson, B. Adams, V. Estrada, and A. Freeman, Horizon Report: 2014 K-12 Edition. 2014.

[10] K. Demir and E. Akpınar, "The effect of mobile learning applications on students' academic achievement and attitudes toward mobile learning," Malaysian Online J. Educ. Technol., 2018, https://doi.org/10.17220/mojet.2018.02.004

[11] J. M. Zydney and Z. Warner, "Mobile apps for science learning: Review of research," Comput. Educ., 2016, doi: 10.1016/j.compedu.2015.11.001.

[12] W. N. W. Zakaria, H. Abas, M. Masrom, R. Mohdali, and N. N. N. Mohamed, "Development of self-learning economics app for secondary school students in Malaysia based on information processing model," TEM J., vol. 8, no. 3, pp. 908-914, 2019, doi: 10.18421/TEM8331.

[13] S. Zhang, "Mobile english learning: An empirical study on an APP, English Fun Dubbing," Int. J. Emerg. Technol. Learn., 2016, https://doi.org/10.3991/ijet.v11i12.6314.

[14] C. wen Shen, J. tsung Ho, P. T. M. Ly, and T. chang Kuo, "Behavioural intentions of using virtual reality in learning: perspectives of acceptance of information technology and learning style," Virtual Real., 2019, https://doi.org/10.1007/s10055-018-0348-1.

[15] N. Thongsri, L. Shen, Y. Bao, and I. M. Alharbi, "Integrating UTAUT and UGT to explain behavioural intention to use M-learning: A developing country's perspective,” J. Syst. Inf. Technol., 2018, https://doi.org/10.1108/jsit-11-2017-0107.

[16] S. Wrycza, B. Marcinkowski, and D. Gajda, "The Enriched UTAUT Model for the Acceptance of Software Engineering Tools in Academic Education,” Inf. Syst. Manag., 2017, https://doi.org/10.1080/10580530.2017.1254446.

[17] S. Y. Park, M. W. Nam, and S. B. Cha, "University students' behavioral intention to use mobile learning: Evaluating the technology acceptance model," Br. J. Educ. Technol., vol. 43, no. 4, pp. 592-605, 2012, https://doi.org/10.1111/j.1467-8535.2011.01229.x

[18] K. A. Barreh and Z. W. Abas, "A Framework for Mobile Learning for Enhancing Learning in Higher Education," Malaysian Online J. Educ. Technol., 2015.

[19] H. Albadry, "An investigation into the role of tablet devices in facilitating collaborative learning in EFL language course," Int. J. Emerg. Technol. Learn., 2017, https://doi.org/10. 3991/ijet.v12i04.6732

[20] B. N. Ireri and E. I. Omwenga, "Modelling an Institutional Mobile Learning Readiness Analyser," J. Educ. Pract., 2015.

[21] D. Frohberg, C. Göth, and G. Schwabe, "Mobile Learning projects - a critical analysis of the state of the art: Original article," J. Comput. Assist. Learn., 2009, https://doi.org/10. $\underline{1111 / \mathrm{j} .1365-2729.2009 .00315 . \mathrm{x}}$

[22] M. Kearney, S. Schuck, K. Burden, and P. Aubusson, "Viewing mobile learning from a pedagogical perspective," Res. Learn. Technol., 2012, https://doi.org/10.3402/rlt.v20i0. $\underline{14406}$

[23] L. Briz-Ponce, A. Pereira, L. Carvalho, J. A. Juanes-Méndez, and F. J. García-Peñalvo, "Learning with mobile technologies - Students' behavior," Comput. Human Behav., vol. 72, pp. 612-620, 2017, https://doi.org/10.1016/j.chb.2016.05.027

[24] L. Naismith, P. Lonsdale, G. Vavoula, and M. Sharples, Literature Review in Mobile Technologies and Learning: Report 11. 2004. 
[25] Y. Zakaria, H. Norman, N. Yasmin Khairani Zakaria, H. Zaini, and F. Hamdan, "Mobile Game-based Learning for Online Assessment in Collaborative Learning," Int. J. Eng. Technol., 2018.

[26] T. C. Liu, Y. C. Lin, and F. Paas, "Effects of cues and real objects on learning in a mobile device supported environment," Br. J. Educ. Technol., 2013, doi: 10.1111/j.14678535.2012.01331 x.

[27] T. C. Liu, Y. C. Lin, and F. Paas, "Effects of prior knowledge on learning from different compositions of representations in a mobile learning environment," Comput. Educ., 2014, https://doi.org/10.1016/j.compedu.2013.10.019

[28] N. D. Ward, R. J. Finley, R. G. Keil, and T. G. Clay, "Benefits and limitations of iPads in the high school science classroom and a trophic cascade lesson plan," J. Geosci. Educ., 2013, doi: $10.5408 / 13-008.1$.

[29] C. P. Lin, L. H. Wong, and Y. J. Shao, "Comparison of 1:1 And 1:M CSCL environment for collaborative concept mapping,” J. Comput. Assist. Learn., 2012, doi: 10.1111/j.13652729.2011.00421 x.

[30] M. M. Riconscente, "Results from a controlled study of the iPad fractions game motion math," Games Cult., 2013, https://doi.org/10.1177/1555412013496894

[31] N. F. Taharim, A. M. Lokman, A. Hanesh, and A. A. Aziz, "Feasibility study on the readiness, suitability and acceptance of M-Learning AR in learning History," in AIP Conference Proceedings, 2016, https://doi.org/10.1063/1.4940257

[32] F. D. Davis, "A technology acceptance model for empirically testing new end-user information systems: Theory and results," 1985.

[33] I. Ajzen, "The theory of planned behavior," Organ. Behav. Hum. Decis. Process., vol. 50, no. 2, pp. 179-211, Dec. 1991, https://doi.org/10.1016/0749-5978(91)90020-t

[34] E. M. Rogers, Diffusion of Innovations-Fourth Edition. 1995.

[35] V. Venkatesh, M. G. Morris, G. B. Davis, and F. D. Davis, "User acceptance of information technology: Toward a unified view," MIS Q. Manag. Inf. Syst., 2003, https://doi. org/10.2307/30036540

[36] T. Teo and J. Noyes, "Explaining the intention to use technology among pre-service teachers: a multi-group analysis of the Unified Theory of Acceptance and Use of Technology," Interact. Learn. Environ., 2014, https://doi.org/10.1080/10494820.2011.641674

[37] T. Sundaravej, "Empirical Validation of Unified Theory of Acceptance and Use of Technology Model,” J. Glob. Inf. Technol. Manag., vol. 13, no. 1, p. 16, 2003.

[38] V. Venkatesh and F. D. Davis, "Theoretical extension of the Technology Acceptance Model: Four longitudinal field studies," Manage. Sci., 2000, doi: 10.1287/mnsc.46.2.186.11926.

[39] H. Y. Wang and S. H. Wang, "User acceptance of mobile internet based on the unified theory of acceptance and use of technology: Investigating the determinants and gender differences," Soc. Behav. Pers., 2010, https://doi.org/10.2224/sbp.2010.38.3.415

[40] V. Terzis and A. A. Economides, "Computer based assessment: Gender differences in perceptions and acceptance," Comput. Human Behav., 2011, doi: 10.1016/j.chb.2011.06.005.

[41] Ali, R.A. and Arshad, M.R.M., "Perspectives of Students Behavior Towards Mobile Learning Mlearning in Egypt An Extension of The UTAUT Model," Engineering Technology \& Applied Science Research. 2016, doi: 412.

[42] N. P. Chin, Wynne, "Structural Equation Modeling Analysis with Small Samples Using Partial Least Square," Stat. Strateg. small sample Res., 1999.

[43] J. Hulland, "Use of partial least squares (PLS) in strategic management research: a review of four recent studies," Strateg. Manag. J., 1999, https://doi.org/10.1002/(sici)10970266(199902)20:2<195::aid-smj13>3.0.co;2-7 
[44] R. P. Bagozzi and Y. Yi, "On the evaluation of structural equation models," J. Acad. Mark. Sci., 1988, doi: 10.1007/BF02723327.

[45] J. Hair, W. Black, B. Babin, and R. Anderson, "Multivariate Data Analysis: A Global Perspective," in Multivariate Data Analysis: A Global Perspective, 2010.

[46] C. Fornell and D. F. Larcker, "Evaluating structural model with unobserved variables and measurement errors," J. Mark. Res., 1981.

[47] M. Ebner, "Interactive lecturing by integrating mobile devices and micro-blogging in higher education,” J. Comput. Inf. Technol., 2009, https://doi.org/10.2498/cit.1001382.

[48] "Curricular Use of the iPad 2 by a First-Year Undergraduate Learning Community," Libr. Technol. Rep., 2012.

[49] D. Nincarean, M. B. Alia, N. D. A. Halim, and M. H. A. Rahman, "Mobile Augmented Reality: The Potential for Education," Procedia - Soc. Behav. Sci., 2013, https://doi.org/10. $\underline{1016 / j . s b s p r o .2013 .10 .385}$

\section{Authors}

Dr. Wan Mohd Amir Fazamin Wan Hamzah is a Senior Lecturer at the Faculty of Informatics and Computing, Universiti Sultan Zainal Abidin (UniSZA), Malaysia. His research areas include learning analytics, e-learning, gamification, and machine learning.

Associate Professor Dr. Mohd Hafiz Yusoff is an Associate Professor at the Faculty of Informatics and Computing, Universiti Sultan Zainal Abidin (UniSZA), Malaysia. He has worked for several years in the areas of e-learning system development and currently working on knowledge management system. (E-mail: hafizyusoff@ unisza.edu.my).

Dr. Ismahafezi Ismail is a Senior Lecturer at the Faculty of Informatics and Computing, Universiti Sultan Zainal Abidin (UniSZA), Malaysia. His research focuses on computer games, computer animation, virtual reality, and augmented reality. (E-mail: ismahafezi@unisza.edu.my).

Dr. Azliza Yacob is a lecturer and researcher at Terengganu Advanced Technical Institute University College (TATiUC). Her research interests include Computer programming, Quality control, education, and computer industry. Her main research concentrates on Knowledge Management system. (E-mail: azliza@tatiuc.edu.my).

Article submitted 2020-01-04. Resubmitted 2020-02-20. Final acceptance 2020-02-23. Final version published as submitted by the authors. 